\title{
Protonation Processes and Electronic Spectra of Histidine and Related Ions
}

\author{
Zhijian Huang, Zijing Lin* and Ce Song \\ Hefei National Laboratory for Physical Sciences at Microscale and Department of Physics, \\ University of Science and Technology of China, Hefei, China 230026 \\ * To whom correspondence should be addressed. E-mail: zjlin@ ustc.edu.cn.
}

Table S1. UV excitation energies (eV) and dipole transition oscillator strengths of the second stable conformers of histidine, histidine tautomer and protonated histidine species.

Figure S1. Simulated IR spectra of the most stable conformers of tautomers of neutral, deprotoated and protonated histidines. The IR bands are Gaussians with the full width at half maximum (FWHM) of $10 \mathrm{~cm}^{-1}$. (A) Fingerprint region; (B) High frequency vibration region.

Figure S2. The representative orbitals of the most stable conformer of histidine tautomer $\operatorname{His}^{\delta}\left[\mathrm{N}^{\delta} \mathrm{H}\right]$. Figure S3. The representative orbitals of the most stable conformer of protonated histidine tautomer $\mathrm{HisH}^{+}\left[\mathrm{NH}_{2}\right]$.

Figure S4. The representative orbitals of the most stable conformer of doubly protonated histidine $\mathrm{HisH}_{2}^{2+}$ 
Table S1. UV excitation energies in $\mathrm{eV}$ and dipole transition oscillator strengths of the second stable conformers of histidine, histidine tautomer and protonated histidine species.

\begin{tabular}{|c|c|c|c|c|c|}
\hline state & $\operatorname{His}\left[\mathrm{N}^{\varepsilon} \mathrm{H}\right]$ & $\operatorname{His}\left[\mathrm{N}^{\delta} \mathrm{H}\right]$ & $\mathrm{HisH}^{+}\left[\mathrm{NH}_{2}\right]$ & $\mathrm{HisH}^{+}\left[\mathrm{N}^{\delta}\right]$ & $\mathrm{HisH}_{2}{ }^{2+}$ \\
\hline $\mathrm{S}_{1}$ & $5.44 / 0.0002$ & $4.53 / 0.0033$ & $5.23 / 0.0021$ & $5.43 / 0.0116$ & $5.61 / 0.0036$ \\
\hline $\mathrm{S}_{2}$ & $5.54 / 0.0018$ & $5.24 / 0.0158$ & $5.69 / 0.0118$ & $5.77 / 0.0002$ & $5.73 / 0.0197$ \\
\hline$S_{3}$ & $5.98 / 0.0462$ & $5.52 / 0.0014$ & $5.73 / 0.0007$ & $5.84 / 0.0036$ & $6.28 / 0.1371$ \\
\hline
\end{tabular}

Figure S1. Simulated IR spectra of the most stable conformers of tautomers of neutral, deprotoated and protonated histidines. The IR bands are Gaussians with the full width at half maximum (FWHM) of $10 \mathrm{~cm}^{-1}$. (A) Fingerprint region; (B) High frequency vibration region.

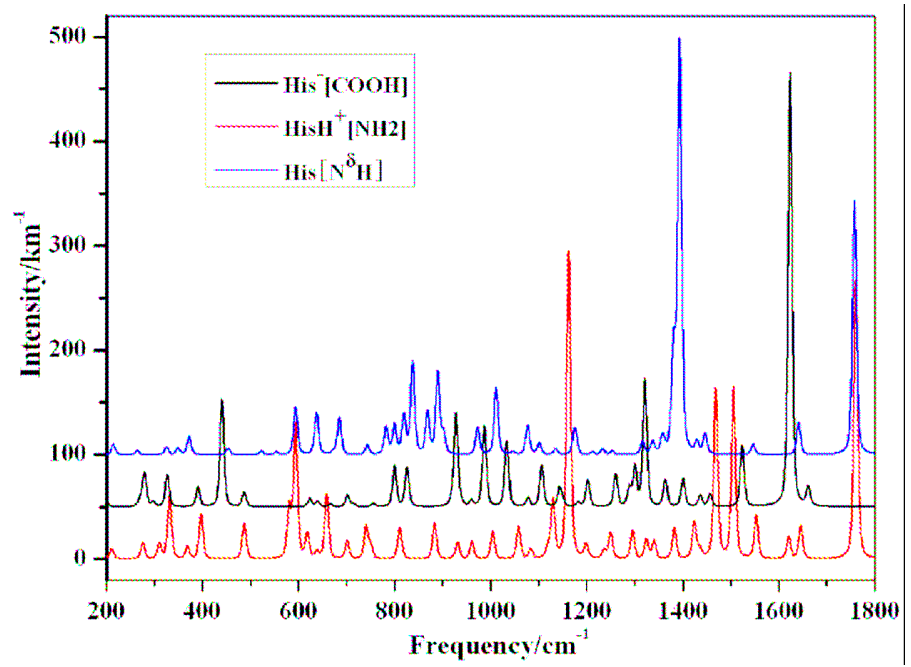

(A) Fingerprint region

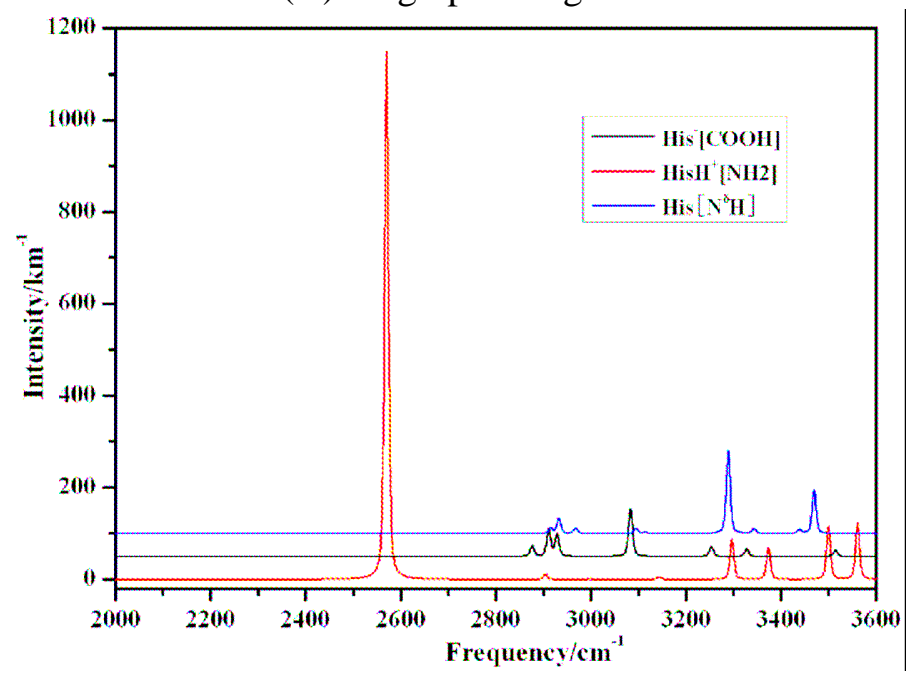

(B) High frequency vibration region. 
Figure S2. The representative orbitals of the most stable conformer of histidine tautomer $\operatorname{His}\left[\mathrm{N}^{\delta} \mathrm{H}\right]$.

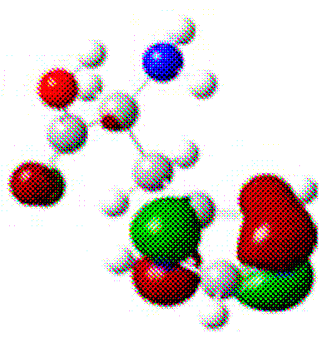

$\mathrm{HOMO}-3$

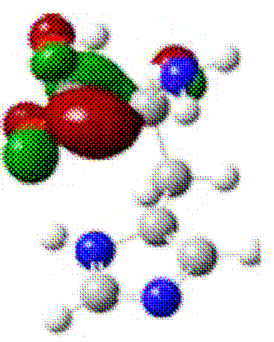

LUMO

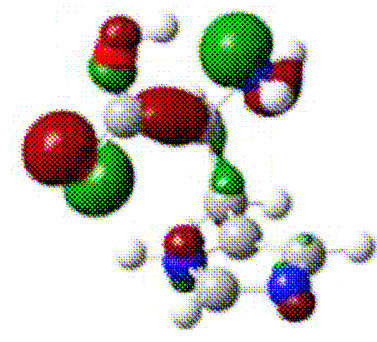

HOMO.2

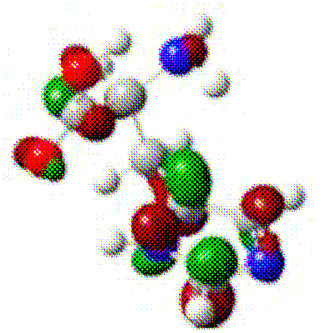

LUMO+1

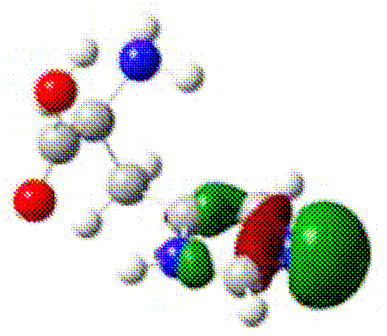

HOMO-1

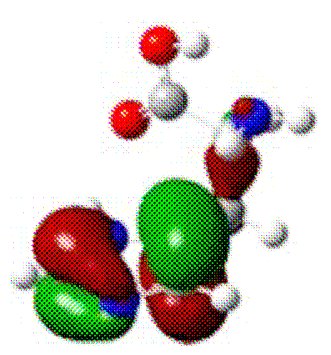

HOMO

Figure S3. The representative orbitals of the most stable conformer of protonated histidine tautomer $\mathrm{HisH}^{+}\left[\mathrm{NH}_{2}\right]$.

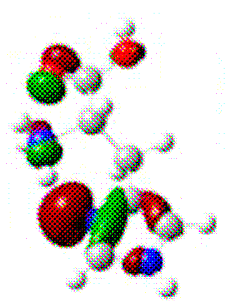

HOMO 3

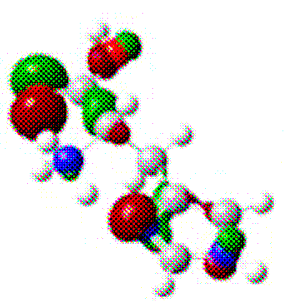

$\mathrm{HOMO}-2$

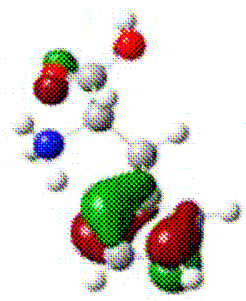

HOMO-1

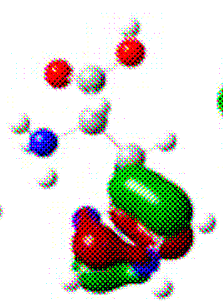

HOMO

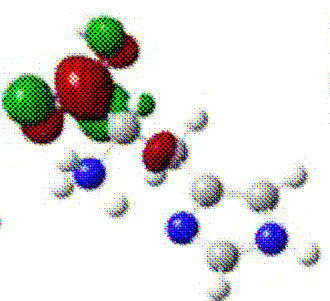

LUMO

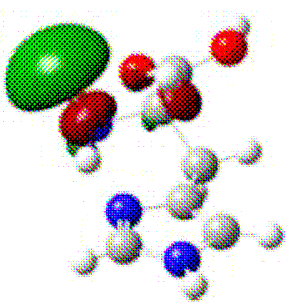

LUMO+1

Figure S4. The representative orbitals of the most stable conformer of doubly protonated histidine $\mathrm{HiSH}_{2}{ }^{2+}$

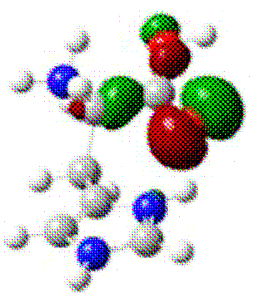

HOMO-1

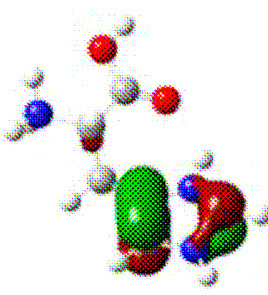

HOMO

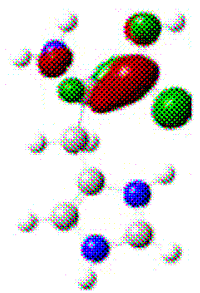

LUMO

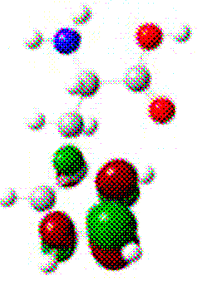

LUMO 1

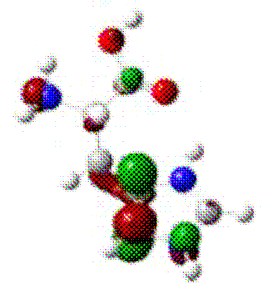

$\mathrm{LUMO}^{2} 2$

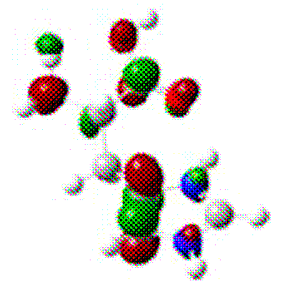

LUMO +3 